\title{
COMPARISON OF THE WAYS OF ACCEPTANCE STUDENTS AT UNIVERSITY
}

Jindřich Klůfa ${ }^{1 凶}$

${ }^{1 \otimes}$ Department of Mathematics, Faculty of Informatics and Statistics, University of Economics, W. Churchill Sq. 4, Prague, 130 67, Czech Republic, +420 224094 244, klufa@vse.cz

\section{Highlights}

- $\quad$ Dependence of the study results at University on the ways of acceptance students

\begin{abstract}
The paper reports on an analysis of the entrance examinations at the Faculty of Informatics and Statistics at University of Economics in Prague. Applicants can be accepted to this faculty by three ways. The aim of this paper is to compare these ways of acceptance students at the Faculty of Informatics and Statistics at University of Economics in Prague and to study dependence of the results of entrance examinations in mathematics on test variants. Results of this analysis can be used for improvement of the entrance examinations at the Faculty of Informatics and Statistics at University of Economics in coming years.
\end{abstract}

\section{Keywords}

Analysis of variance, course Mathematics for economists and course Mathematics for informatics and statistics, entrance examinations, Kruskal-Wallis test, Scheffe's method, test of independence in contingency table

\section{Article type}

Full research paper

Article history

Received: June 12, 2015

Received in revised form: August 07, 2015

Accepted: August 11, 2015

Available on-line: November 24, 2015

Klüfa J. (2015) “Comparison of The Ways of Acceptance Students at University”, Journal on Efficiency and Responsibility in Education and Science, Vol. 8, No. 3, pp. 72-76, online ISSN 1803-1617, printed ISSN 2336-2375, doi: 10.7160/eriesj.2015.080204.

\section{Introduction}

Applicants can be accepted to study Faculty of Informatics and Statistics at University of Economics in Prague by three ways:

- on the base of tests in mathematics and English, which is used at University of Economics in Prague (VSE tests)

- on the base of the national comparative exams - the tests of general academic prerequisites (SCIO tests)

- without entrance examinations (on the base of results in mathematics and English at grammar school etc.).

The relations between the ways of acceptance applicants to study Faculty of Informatics and Statistics and study results in mathematics are studied in this paper. Similar problem (the dependence of study results and results of the learning potential tests) is solved in Kubanová and Linda (2012), Linda and Kubanová (2013). On the other hand, analysis of the study results in basic courses in mathematics at University of Economics is in Kaspř́k ková (2012), Otavová and Sýkorová (2014). This paper is an extended version of the paper Klůfa (2015) - other group of students was analyzed.

In the second place we shall study dependence of the results of entrance examinations in mathematics on test variants. The math tests are prepared by the Department of Mathematics of the Faculty of Informatics and Statistics. These tests are the multiple choice question tests. The tests in mathematics have 10 questions for 5 points and 5 questions for 10 points (100 points total). Questions are independent. Each question has 5 answers (one answer is correct), wrong answer is not penalized. The number of points in the test in mathematics can be

$$
0,5,10,15,20,25,30,35,40,45, \ldots, 90,95,100
$$

These tests are used to the three faculties of the Prague University of Economics (Faculty of Informatics and Statistics, Faculty of Finance and Accounting, Faculty of Business Administration). The multiple choice question tests for entrance examinations at University of Economics in Prague from probability point of view are analysed in Klůfa (2013), Klůfa and Kaspř́iková (2012), Klůfa (2012).

The second aim of this paper is to analyse the entrance examinations in mathematics (similar problems are solved in Brožová and Rydval (2013), Hrubý (2013), Mošna (2013), Kučera, Svatošová and Pelikán (2015)) at the Faculty of Informatics and Statistics at University of Economics in Prague from point of view test variants. We shall study dependence of number of points in the test in mathematics on test variants. These results will be used to further improve of the preparation of test variants in coming years.

\section{Material and Methods}

The analysed data are the results of the entrance examinations of 849 applicants in mathematics. Four test variants (denoted A6, A7, B2, B3) were parallely used for the entrance examinations in mathematics at the Faculty of Informatics and Statistics in 2013 (variants are randomly selected immediately before the test). The analysed data are sorted according to test variants (contingency table).

On the other hand the results in mathematics of 104 students in 
summer semester of the 2013/2014 academic year in the course Mathematics for informatics and statistics (ident 4MM103) and the results of 472 students in winter semester of the 2014/2015 academic year in the course Mathematics for economists (ident $4 \mathrm{MM} 101)$ are analysed. The number of points in the test in the course Mathematics for informatics and statistics and in the course Mathematics for economists can be in interval $[0,40]$, the multiple choice question tests are not used. The analysed data

are sorted according to ways of acceptance students to study Faculty of Informatics and Statistics at University of Economics in Prague - see Table 2 and Table 4.

Some statistical methods are used for an analysis of the entrance examinations at the Faculty of Informatics and Statistics - see e.g. Anděl (1978), Rao (1973).

For study dependence of number of points in the test in mathematics on test variants we shall use $\chi^{2}$ test of independence in contingency table. Statistic $\chi^{2}$ is

$$
\chi^{2}=\sum_{i=1}^{r} \sum_{j=1}^{s} \frac{\left(n_{i j}-n_{i j}^{o}\right)^{2}}{n_{i j}^{o}},
$$

where $r$ is number of rows, $s$ is the number of columns in contingency table and $n_{i j}^{o}$ is the expected frequency in case of independence. When

$$
\chi^{2}>\chi_{\alpha}^{2}((r-1)(s-1))
$$

where $\chi_{\alpha}^{2}((r-1)(s-1))$ is critical value of $\chi^{2}$ distribution, hypothesis of independence is rejected at significance level, which is asymptotically equal to $\alpha$.

For comparison of the ways of acceptance applicants to study we shall use nonparametric Kruskal-Wallis test. When (statistic $Q$ see e.g. Anděl (1978: 231))

$$
Q>\chi_{\alpha}^{2}(k-1)
$$

where $\chi_{\alpha}^{2}(k-1)$ is critical value of $\chi^{2}$ distribution for $k-1$ degrees of freedom ( $k$ is number of the ways of acceptance applicants), hypothesis "distribution of number of points in mathematics is the same for all three ways of acceptance students" is rejected at significance level, which is asymptotically equal to $\alpha$.

Further for comparison of the ways of acceptance applicants to study we shall use a one-way analysis of variance (ANOVA). We shall verify the validity of the null hypothesis: mean number of points in mathematics is the same for all three ways

of acceptance students. When (the test statistic $F$ see e.g. Rao (1973: 280))

$$
F>F_{\alpha}(k-1, n-k)
$$

where $F_{\alpha}(k-1, n-k)$ is critical value of Fischer-Snedecor distribution with $(k-1)$ and $(n-k)$ degrees of freedom $(k=3)$, hypothesis is rejected at significance level $\alpha$.

\section{Results}

\begin{tabular}{|c|c|c|c|c|c|}
\hline \multirow{2}{*}{$\begin{array}{c}\text { Points in } \\
\text { test }\end{array}$} & \multicolumn{4}{|c|}{ Variants } & \multirow[b]{2}{*}{ Sum } \\
\hline & A6 & A7 & B2 & B3 & \\
\hline 0 & 2 & 1 & 0 & 1 & 4 \\
\hline 5 & 2 & 0 & 0 & 2 & 4 \\
\hline 10 & 6 & 3 & 1 & 6 & 16 \\
\hline 15 & 4 & 4 & 2 & 8 & 18 \\
\hline 20 & 9 & 7 & 7 & 7 & 30 \\
\hline 25 & 12 & 10 & 8 & 6 & 36 \\
\hline 30 & 18 & 10 & 8 & 11 & 47 \\
\hline 35 & 15 & 9 & 16 & 16 & 56 \\
\hline 40 & 22 & 17 & 21 & 10 & 70 \\
\hline 45 & 19 & 18 & 21 & 15 & 73 \\
\hline 50 & 17 & 13 & 22 & 19 & 71 \\
\hline 55 & 15 & 14 & 17 & 15 & 61 \\
\hline 60 & 17 & 14 & 12 & 15 & 58 \\
\hline 65 & 26 & 12 & 19 & 9 & 66 \\
\hline 70 & 9 & 9 & 11 & 13 & 42 \\
\hline 75 & 11 & 10 & 17 & 11 & 49 \\
\hline 80 & 7 & 12 & 13 & 10 & 42 \\
\hline 85 & 3 & 13 & 11 & 7 & 34 \\
\hline 90 & 5 & 7 & 10 & 5 & 27 \\
\hline 95 & 0 & 5 & 4 & 7 & 16 \\
\hline 100 & 5 & 11 & 7 & 6 & 29 \\
\hline Sum & 224 & 199 & 227 & 199 & 849 \\
\hline
\end{tabular}

\section{Dependence on test variants}

Results of the entrance examinations in mathematics in 2013 are in Table 1 (for example 6)

Tab. 1: Distribution of number of points in test in mathematics (contingency table)

students with variant $\mathrm{A} 6$ obtained 10 points in test in mathematics, i.e. 6 is absolute frequency $n_{31}$ in 3 rd row and 1 st column of the contingency table) and Figure 1.

Now we shall study dependence of number of points in the test in mathematics on test variants. Null hypothesis is

$\mathrm{H}_{\mathrm{o}}$ : number of points in the test is not dependent on the test variant.

$\chi^{2}$ test of independence in contingency table is used for the decision on the validity of the hypothesis $H_{0}$. In the first step we calculate according to (1) statistic $\chi^{2}$ (for example $n_{11}=2$ (see Tab.1) and expected frequency $\left.n_{11}^{o}=4 \times 224 / 849=1.055\right)$. Because of the small expected frequencies, we combine first 3 rows of the contingency table. We have

$$
\chi^{2}=63.89
$$

Critical value of $\chi^{2}$ distribution for 54 degrees of freedom and significance level $\alpha=0.05$ is $\chi_{0.05}^{2}(54)=72.15$. Since

$$
\chi^{2}=63.89<72.15,
$$

null hypothesis $\mathrm{H}_{\mathrm{o}}$ is not rejected at approximately $5 \%$ 
significance level. Moreover $p$ value is 0.168 (null hypothesis $\mathrm{H}_{\mathrm{o}}$ is not rejected also at $16 \%$ significance level). For calculation

we used MS Excel version 10 - see Marek (2013). We can say that the number of points in the test does not depend on the test variant.

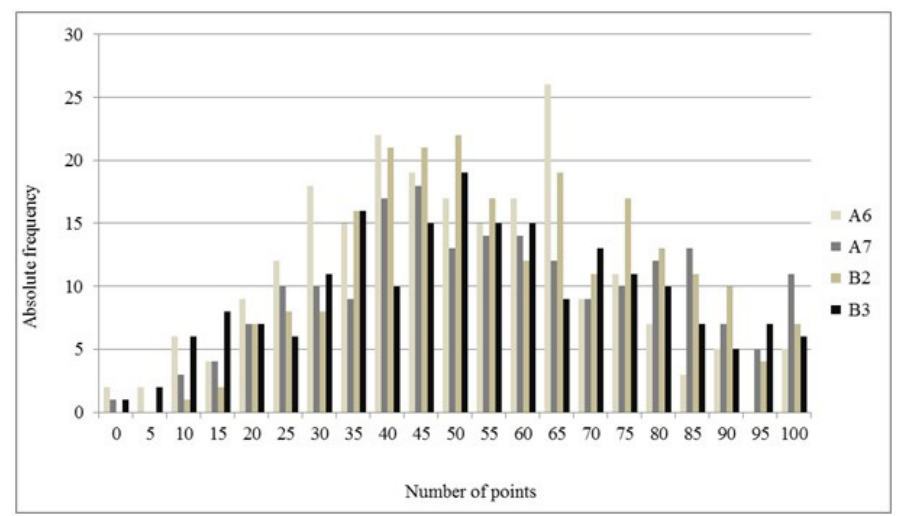

Fig. 1: Distribution of number of points in test in mathematics in 2013 - test variants A6, A7, B2, B3 (histogram)

\section{Differences between the ways of acceptance applicants}

Now we shall compare the ways of acceptance applicants to study Faculty of Informatics and Statistics. Results in mathematics in the course Mathematics for informatics and statistics sorted according to the ways of acceptance applicants are in Table 2 (see Appendix).

We shall test null hypothesis

$\mathrm{H}_{\mathrm{o}}$ : distribution of number of points in mathematics is the same

for all three ways of acceptance students (VSE tests, SCIO tests, other)

Some parameters of distribution of number of points in mathematics are in Table 3. From Table 3 it seems that the distributions of number of points in mathematics (VSE tests, SCIO tests, other) differ, i.e. hypothesis $\mathrm{H}_{\mathrm{o}}$ is not valid. For objective decision we shall use a statistical test. To verify the validity of the hypothesis $H_{0}$ we shall use Kruskal-Wallis nonparametric test.

\begin{tabular}{|l|c|c|c|}
\hline & VSE Tests & SCIO Tests & Other \\
\hline Average & 27.119 & 22.182 & 31.039 \\
\hline Median & 28.000 & 23.000 & 32.000 \\
\hline Modus & 28.000 & 19.000 & 32.000 \\
\hline Std. Deviation & 8.500 & 10.944 & 6.135 \\
\hline Kurtosis & -0.248 & -0.215 & -0.095 \\
\hline Skewness & -0.496 & -0.633 & -0.550 \\
\hline
\end{tabular}

Tab. 3: Descriptive statistics for number of points in the course 4MM103

Value of statistic $Q$ is ( $Q$ is calculated on the base of rank of values in Table 2 - see Anděl (1978: 231))

$$
Q=9.95
$$

This statistic has asymptotically $\chi^{2}$ distribution for 2 degrees of freedom. Critical value of $\chi^{2}$ distribution for two degrees of freedom and significance level $\alpha=0.01$ is $\chi_{0.01}^{2}(2)=9.21$. Since

$$
Q=9.95>9.21 \text {, }
$$

null hypothesis is rejected at significance level, which is approximately equal to $\alpha=0.01$. With high probability (approximately 0.99), we can say that there are significant differences between ways of acceptance students to study Faculty of Informatics and Statistics (VSE tests, SCIO tests, other).

Remark. Similar result gives ANOVA: null hypothesis "mean number of points in test in the course Mathematics for informatics and statistics is the same for all three ways of acceptance students" is rejected $(F=7.088>4.822)$ at significance level $\alpha=0.01-$ see Tab. 5. Assumption of ANOVA: null hypothesis "variance of number of points is the same for all three ways of acceptance students" is not rejected at 1\% significance level (Bartlett's test - see e.g. Anděl (1978: 155)). Since this hypothesis is rejected at 5\% significance level, we used also corresponding nonparametric Kruskal-Wallis test.

\begin{tabular}{|l|c|c|c|c|c|c|}
\hline $\begin{array}{l}\text { Source of } \\
\text { variability }\end{array}$ & $\begin{array}{c}\text { Sum of } \\
\text { Squares }\end{array}$ & $\begin{array}{c}\text { Degrees } \\
\text { of } \\
\text { freedom }\end{array}$ & Fraction & F & P value & F crit \\
\hline $\begin{array}{l}\text { Ways of } \\
\text { acceptance }\end{array}$ & 847.999 & 2 & 423.999 & 7.088 & 0.001 & 4.822 \\
\hline Rezidual & 6041.96 & 101 & 59.8214 & & & \\
\hline Sum & 6889.96 & 103 & & & & \\
\hline
\end{tabular}

Tab. 5: Results of ANOVA for course 4MM103

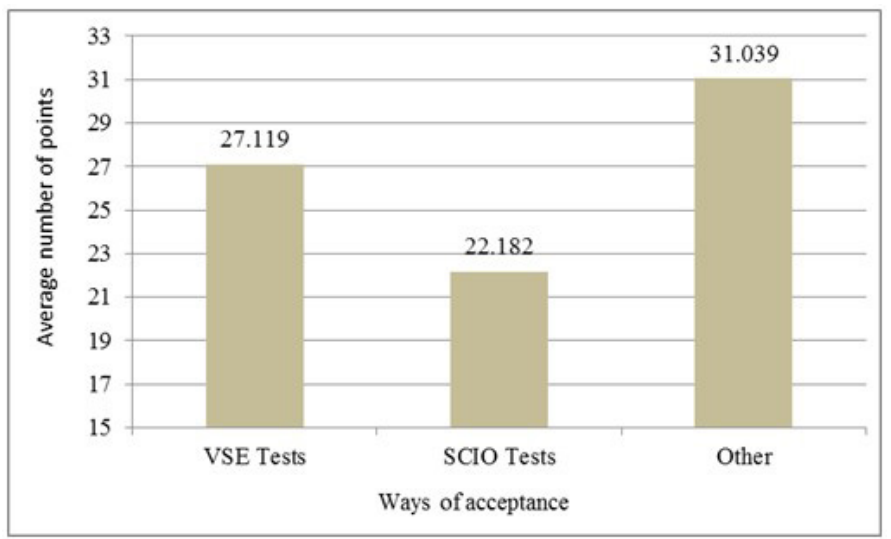

Fig. 2: Average number of points in test in mathematics in the course 4MM103

Finally we shall study which pairs of averages differ significantly. We use Scheffe's method - see e.g. Anděl (1978: 154). Pairs of averages differ significantly if absolute value of difference in averages exceeds critical value (see Tab. $2\left(n_{1}=42, n_{2}=11, n_{3}=51\right)$ and Tab. 5)

$$
\sqrt{\left(\frac{1}{n_{i}}+\frac{1}{n_{j}}\right) \times 2 \times 59.8214128 \times 4.821677}
$$

\begin{tabular}{|c|c|c|}
\hline Pair of test variants & $\begin{array}{c}\text { Absolute value } \\
\text { of difference in } \\
\text { averages }\end{array}$ & Critical value (9) \\
\hline VSE tests, SCIO tests & 4.937 & 8.135 \\
\hline VSE tests, Other & 3.920 & 5.005 \\
\hline SCIO tests, Other & $8.857 *$ & 7.985 \\
\hline
\end{tabular}

* Significant difference for $\alpha=\mathbf{0 . 0 1}$

Tab. 6: Scheffé's method 
From Tab. 6 it is seen that a significant difference is at $1 \%$ significant level only between SCIO tests and Other.

On the other hand, results in mathematics in the course Mathematics for economists (ident 4MM101) sorted according to the ways of acceptance applicants are in Table 4 (see Appendix). We shall test null hypothesis

$$
\mathrm{H}_{\mathrm{o}}: \mu_{1}=\mu_{2}=\mu_{3} \text {, }
$$

i.e. mean number of points in test in the course Mathematics for economists is the same for all three ways of acceptance students (VSE tests, SCIO tests, other).

\begin{tabular}{|c|c|c|c|c|}
\hline $\begin{array}{c}\text { Ways of } \\
\text { acceptance }\end{array}$ & Frequency $\mathrm{n}_{\mathrm{i}}$ & Sum & $\begin{array}{c}\text { Average number } \\
\text { of points }\end{array}$ & Variance \\
\hline VSE tests & 305 & 7276 & 23.85574 & 100.3804 \\
\hline SCIO tests & 58 & 1361 & 23.46552 & 104.8497 \\
\hline Other & 109 & 2876 & 26.38532 & 113.0724 \\
\hline
\end{tabular}

Tab. 7: Descriptive statistics for number of points in the course 4MM101

To verify the validity of the hypothesis (10) we use ANOVA. In the first step we verify assumption (the same variance of number of points in ways of acceptance) of this method by Bartlett's test. Test statistic $B$ (see e.g. Anděl $(1978: 155)$ ) is $B=0.58$. Critical value of $\chi^{2}$ distribution for 2 degrees of freedom and significance level $\alpha=0.05$ is $\chi_{0.05}^{2}(2)=5$.99. Since

$$
B<5.99
$$

assumption of ANOVA can be considered to have been met (the differences between variance

$$
s_{V S E}^{2}=100.38, \quad s_{S C I O}^{2}=104.85, \quad s_{\text {Other }}^{2}=113.07
$$

in the course Mathematics for economists (see last column of Tab. 7) are not statistically significant).

Results of ANOVA we got with MS Excel - see Tab. 8.

\begin{tabular}{|l|c|c|c|c|c|c|}
\hline $\begin{array}{l}\text { Source of } \\
\text { variability }\end{array}$ & $\begin{array}{c}\text { Sum of } \\
\text { Squares }\end{array}$ & $\begin{array}{c}\text { Degrees } \\
\text { of } \\
\text { freedom }\end{array}$ & Fraction & F & P value & F crit \\
\hline $\begin{array}{l}\text { Ways of } \\
\text { acceptance }\end{array}$ & 570.59 & 2 & 285.29 & 2.75 & 0.065 & 3.015 \\
\hline Rezidual & 48703.9 & 469 & 103.85 & & & \\
\hline Sum & 49274.49 & 471 & & & & \\
\hline
\end{tabular}

Tab. 8: Results of ANOVA for course 4MM101

Since

$$
F=2.747<3.015 \text {, }
$$

null hypothesis (10) is not rejected at 5\% significance level. The differences between average number of points in test

$$
\bar{x}_{V S E}=23.86, \quad \bar{x}_{\text {SCIO }}=23.47, \quad \bar{x}_{\text {Other }}=26.39
$$

in the course Mathematics for economists (see Tab. 7) are not statistically significant.

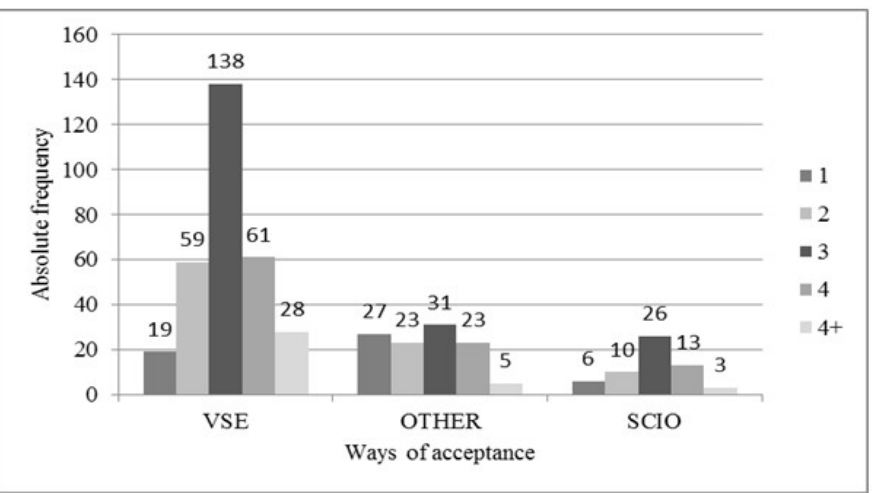

Fig. 3: Distribution of the final results (test + oral exam) in mathematics in course 4MM101 - ways of acceptance (histogram)

\section{Discussion}

Similar problem as in this paper is solved in Kubanová and Linda (2012). There is studied the dependence of study results and results of the learning potential tests (SCIO tests). The insignificant correlation was detected between results in learning potential test and study results. In this paper was solved other problem - dependence between study results in mathematics and SCIO tests (ways of acceptance students) has been proven.

On the other hand, analysis of the study results in basic courses in mathematics at University of Economics is in Otavová and Sýkorová (2014). There is studied whether the score from final test depends on the score from mid-term test. Similar methods as in this paper show that dependence between the score from final test and the score from mid-term test exists.

The multiple choice question tests for entrance examinations at University of Economics in Prague from probability point of view are analysed in Klůfa and Kaspř́ková (2012). Disadvantages of such type of test is that a student can obtain certain number of points in the test purely by guessing the correct answers. Results of the paper show that risk of success of students with lower performance levels is negligible. The analysis of entrance examinations in this paper (the dependence on the test variants) also shows that these tests are suitable for entrance examinations at University of Economics.

Relation between results of the entrance examination test in mathematics and examination in mathematics at University of Pardubice is studied in Linda and Kubanová (2013). This paper had demonstrated the dependence of the test results in math on the results of entrance tests in mathematics (in contrast to SCIO tests). This finding should lead to the conclusion that the schools should focus on admission process, students should be accepted on the basis of own admission. Similar results we obtain also in this paper.

\section{Conclusion}

From $\chi^{2}$ test of independence in contingency table it follows that the number of points in the test in mathematics does not depend on the test variant. From the results of this paper we can say that significant changes in test variants in mathematics in the coming years are not needed.

There are significant differences between students which were accepted to study Faculty of Informatics and Statistics on the base VSE tests, SCIO test and without entrance examinations from the point of view test score in mathematics (see also Figure 2 ). The best results from the point of view number of points in 
test in mathematics in the course 4MM103 achieved by students which were accepted on the base of good results in mathematics and English at grammar school (without entrance examinations).

On the other hand, the differences between average number of points in test in the course Mathematics for economists (ident 4MM101) are not statistically significant.

For the eventual changes in the admission process, it would be useful to test the differences between ways of acceptance students to study Faculty of Informatics and Statistics in other courses.

From results of this paper it seems that applicants should be accepted to study Faculty of Informatics and Statistics at University of Economics in Prague on the basis of own admission process.

\section{Acknowledgements}

This paper was processed with contribution of long term institutional support of research activities by Faculty of Informatics and Statistics, University of Economics, Prague.

\section{References}

Anděl, J. (1978) Matematická statistika. Praha: SNTL/ALFA.

Brožová, H., Rydval, J. (2013) 'Analysis of the exam test quality', Efficiency and Responsibility in Education, Proceedings of the 10th International Conference, Prague, pp. 47-54.

Hrubý, M. (2013) 'Extended elements of the question objects', Efficiency and Responsibility in Education, Proceedings of the 10th International Conference, Prague, pp. 204-209.

Kaspř́ḱková, N. (2012) 'Data analysis of students' performance', Efficiency and Responsibility in Education, Proceedings of the 9th International Conference, Prague, pp. 213-218.

Klůfa, J. (2012) 'Tests from probability point of view', Efficiency and Responsibility in Education, Proceedings of the 9th International Conference, Prague, pp. 229-233.

Klůfa, J., Kaspř́ková, N. (2012) 'Multiple Choice Question Tests for Entrance Examinations - A Probabilistic Approach', Journal on Efficiency and Responsibility in Education and Science, vol. 5, no. 4, pp. 195-202. http://dx.doi.org/10.7160/ eriesj.2012.050402

Klůfa, J. (2013) 'Comparison of entrance examinations in mathematics', Efficiency and Responsibility in Education, Proceedings of the 10th International Conference, Prague, pp. 270-275.

Klůfa, J. (2015) 'Analysis of entrance examinations, Efficiency and Responsibility in Education, Proceedings of the 12th International Conference, Prague, pp. 250-256.

Kubanová, J., Linda, B. (2012) 'Relation between results of the learning potential tests and study results', Journal on Efficiency and Responsibility in Education and Science, vol. 5, no 3, pp.125-134. http://dx.doi.org/10.7160/eriesj.2012.050302

Kučera, P., Svatošová, L., Pelikán, M. (2015) 'University study results as related to the admission exam results' Efficiency and Responsibility in Education, Proceedings of the 12th International Conference, Prague, pp. 318-324.

Linda, B., Kubanová, J. (2013) 'Relation between results of the entrance examination test in mathematics and examination in mathematics at the university', Efficiency and Responsibility in Education, Proceedings of the 10th International Conference, Prague, pp. 370-373.

Marek, L. (2013) Statistika v príkladech, Prague: Professional Publishing.
Mošna, F. (2013) 'E-learning and interactive dynamical figures for teaching of mathematics', Efficiency and Responsibility in Education, Proceedings of the 10th International Conference, Prague, pp. 449-454.

Otavová, M., Sýkorová, I. (2014) 'Analysis of Scores from Mid-Term and Final Test by a Contingency Table', Efficiency and Responsibility in Education, Proceedings of the 11th International Conference, Prague, pp. 527-533.

Rao, C.R. (1973) Linear Statistical Inference and Its Applications, New York: John Wiley

\section{Appendix}

\section{VSE tests:}

$9,10,11,11,12,16,20,21,22,23,23,23,23,24,24,26,26,26,27,28,28,28$, $28,28,29,30,30,30,30,32,32,33,34,35,35,38,38,38,39,39,40,40$

\section{SCIO tests:}

$2,6,18,19,19,23,27,29,30,34,37$

\section{Other:}

$14,18,21,22,22,23,24,24,25,25,26,26,27,27,27,28,28,29,30,30,31$, $31,31,31,32,32,32,32,32,32,33,33,33,34,35,35,35,35,36,36,37,38$, $38,38,39,39,39,39,39,40,40$

Tab. 2: Number of points in test in the course 4MM103

\section{VSE tests:}

$0,0,0,0,0,1,2,3,3,4,4,4,4,4,5,5,5,5,5,6,6,6,6,7,8,9,9,9,10,10,10,10$, $10,10,11,11,11,11,11,12,12,12,12,12,12,12,12,13,13,13,13,13,14$ $14,14,14,14,14,14,14,15,15,15,15,15,16,16,16,16,16,17,17,17,17$, $17,17,17,17,17,17,18,18,18,18,18,18,19,19,19,19,19,19,19,19,19$, $19,20,20,20,20,20,20,20,20,20,20,21,21,21,21,21,21,21,21,22,22$, $22,22,22,22,22,22,22,22,22,22,22,23,23,23,23,23,23,23,23,23,23$, $23,23,24,24,24,24,24,24,25,25,25,25,25,25,25,25,25,25,25,25,25$, $25,25,25,26,26,26,26,26,26,26,26,26,26,26,26,26,27,27,27,27,27$, $28,28,28,28,28,28,28,28,28,28,28,28,28,28,29,29,29,29,29,29,29$, $29,29,30,30,30,30,30,30,30,30,30,30,30,30,30,30,30,30,30,30,30$, $30,31,31,31,32,32,32,32,32,32,32,32,32,32,32,32,32,33,33,33,33$, $33,33,33,33,33,33,34,34,34,34,34,34,34,34,34,35,35,35,35,35,35$, $35,35,35,35,36,36,36,36,36,36,36,37,37,37,37,37,38,38,38,38,38$, $38,38,38,38,39,39,39,39,39,39,39,39,39,40,40,40,40,40,40,40,40$

\section{SCIO tests:}

$0,3,4,5,7,7,8,8,9,11,11,13,15,16,17,17,18,19,20,21,22,22,23,24,25$, $25,25,26,26,26,27,27,27,27,28,28,28,29,29,29,29,30,30,30,31,31$, $32,33,34,34,35,35,35,36,37,38,39,40$

\section{Other:}

$3,5,6,7,7,7,8,8,9,9,9,10,11,11,12,13,13,14,14,14,15,15,16,16,18,18$, $18,18,19,19,19,20,20,21,21,22,22,22,23,23,23,24,24,25,25,25,25$, $27,27,27,27,27,27,28,28,28,29,29,29,29,30,30,30,31,31,31,31,31$, $32,32,33,34,34,34,35,35,35,35,36,36,36,36,37,37,37,37,37,37,37$, $37,38,38,38,38,38,39,39,39,39,39,39,40,40,40,40,40,40,40,40$

Tab. 4: Number of points in test in the course 4MM101 